\title{
Glycaemic and appetitive responses to porridge made from oats differing by degree of processing
}

\author{
J. T. Gonzalez and E. J. Stevenson \\ School of Life Sciences, Northumbria University, Newcastle NE1 8ST, UK
}

Postprandial glycaemia is associated with body mass and obesity risk $^{(1)}$. Low glycaemic index (GI) meals have been shown to enhance lipid utilisation and satiety ${ }^{(2)}$. Steel-cut (SC) oats produce a lower glycaemic response than rolled (R) oats, with the same nutritional content, when boiled in water ${ }^{(3)}$. Yet, the application of this for the general population is limited as many individuals prefer porridge made with milk and a sweetener. Accordingly, the aim of this study was to compare the glycaemic and appetitive responses to porridges made with SC and R oats, milk and sweetened with honey.

In a randomised, crossover design, separated by at least $2 \mathrm{~d}$, ten healthy participants [8M, $2 \mathrm{~F}$; mean age 25.9 (SD 2.3 ) years, height 178.0(SD 8.2) cm, body mass 76.6(SD 10.6) $\mathrm{kg}$ and BMI 24.2(SD 2.8) kg/m²], consumed porridge made from $150 \mathrm{ml}$ semi-skimmed milk (Tesco, Dundee, UK), $58 \mathrm{~g}$ of either SC or R oats (Healthysupplies.co.uk, Bob's Red Mill, Milwaukee, OR, USA), $100 \mathrm{ml}$ of water and $5 \mathrm{~g}$ honey (Tesco, Dundee, UK). This porridge provides $1359 \mathrm{~kJ}$ and $50 \mathrm{~g}$ of $\mathrm{CHO}$ (18\% protein, $62 \% \mathrm{CHO}, 20 \%$ fat). The porridge was cooked in a microwave oven on full power $(1000 \mathrm{~W})$ for $6 \mathrm{~min}$. After cooking, it was left to cool for 10 min before being served. Following baseline measurements, participants were provided with the test meal along with $250 \mathrm{ml}$ water which they were asked to consume within $10 \mathrm{~min}$. Further measurements were taken 15, 30, 45, 60, 90 and 120 min after the first mouthful was consumed. Capillary blood was sampled in duplicate to determine blood glucose and lactate concentrations (Biosen C_line, EKF Diagnostics, Magdeberg, Germany) and paper-based, visual analogue scales (VAS), were used to determine hunger, fullness, satisfaction, prospective food consumption, tiredness, thirst and jitteriness. Comparisons between meals were made by repeated measures ANOVA and paired samples $t$-tests were used to compare baseline measurements and area under the curve values between trials. Significance was accepted at $P=0.05$.

Baseline glucose and lactate concentrations and appetite ratings were similar on both occasions $(P>0.05)$. Postprandial glycaemia was higher with $\mathrm{R}$ compared with SC $(P<0.01)$. Incremental area under the curve values for blood glucose were higher in response to $\mathrm{R}$ compared with SC [92(SD 59) and 71(SD 43) mmol/1/2 h, respectively; $P<0.05$ ]. However, peak change in blood glucose concentration did not differ between trials [R, 2.38(SD 0.8); SC, 2.29(SD 0.81) mmol/l; $P>0.05$ ] The area under the curve for fullness tended to be higher with R compared with SC [6763(SD 1817) v. 5942(SD 1696) AU, $P=0.08$ ). All other subjective ratings showed no difference between trials (all $P>0.05$ ).

The processing of oats influences the glycaemic response when consumed as a milk-based porridge, with no significant effect on satiety.

1. Thomas DE, Elliot EJ \& Baur L (2007) Low glycaemic index or low glycaemic load diets for overweight and obesity. Cochrane Database of Systematic Reviews. issue 3, CD005105. http://www.mrw.interscience.wiley.com/cochrane/clsysrev/articles/CD005105/frame.html

2. Stevenson EJ, Williams C, Mash LE et al. (2006) Influence of high-carbohydrate mixed meals with different glycaemic indices on substrate utilization during subsequent exercise in women. Am J Clin Nutr 84, 354-360.

3. Granfeldt Y, Hagander B \& Björck I (1995) Metabolic responses to starch in oat and wheat products. On the importance of food structure, incomplete gelatinization or presence of viscous dietary fibre. Eur J Clin Nutr 49, 189-199. 